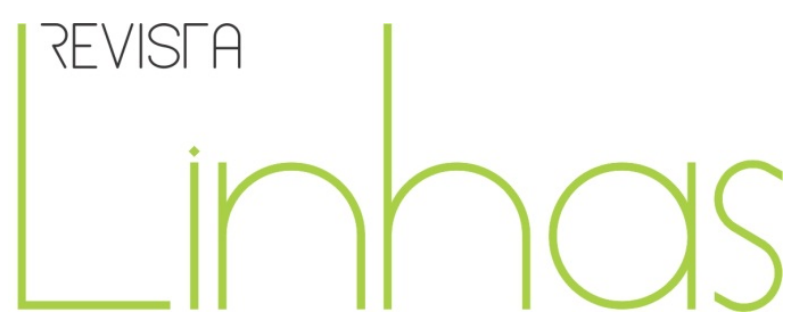

\title{
Rememorando: a formação, a trajetória acadêmica e a profissional
}

\begin{abstract}
Resumo
A presente narrativa apresenta o percurso para a formação, a trajetória Acadêmica e a Profissional de uma professora. Os fios condutores são a Teoria da Complexidade de Edgar Morin e a Epistemologia de Ludwig Fleck, haja vista, a forte influência teórica desses autores na caminhada acadêmica e profissional dessa professora. Inicialmente a elaboração do texto objetivou somente cumprir exigência documental de um editor de processo de seleção docente do PPGE/UNIPLA, mas à medida que a narrativa avançou, foi prazeroso compreender como essa construção foi ocorrendo, as implicações complexas da realidade para o delinear do estilo de pensamento hoje existente. Desta forma foi sendo escrito o memorial, foram surgindo os processos sociais, educacionais, históricos e epistemológicos que contribuíram como fios condutores da formação e trajetória acadêmica e profissional. O movimento entre o específico e as generalidades é marcante, pois foi registrando os contornos de uma profissional da educação comprometida com os alunos e com a qualidade do ensino. Se havia alguma dúvida sobre a participação ou não do citado processo seletivo, ao final deste ficou evidenciado para a autora o quanto ainda há para contribuir com a área da Educação.
\end{abstract}

Palavras-chave: Processos socioculturais. Educação. Memorial.
Lucia Ceccato de Lima

Doutorado em Engenharia Ambiental pela Universidade Federal de Santa Catariana - UFSC. Professora do Programa de Pós-Graduação em Educação da Universidade do Planalto Catarinense - UNIPLAC. ceccato@brturbo.com.br

\section{Para citar este artigo:}

LIMA, Lucia Ceccato de. Rememorando: a formação, a trajetória acadêmica e a profissional.

Revista Linhas, Florianópolis, v. 14, n. 26 , jan./jun. 2013. p. 293 - 311.

DOI: $10.5965 / 1984723814262013293$

http://dx.doi.org/10.5965/1984723814262013293 


\title{
Looking back: the training, academic and professional career
}

\begin{abstract}
This narrative presents the training process, academic and professional career of a teacher. The references for this research were the Complexity Theory of Edgar Morin and the epistemological vision of Ludwik Fleck, given the strong theoretical influence of the authors on this teacher's academic and professional path. Initially the text was prepared only to meet the documentary requirements of an editor of the teacher selection process PPGE/UNIPLA, but as the story progressed, it was delightful to understand how the process took place, the complex implications of reality to determine the current thinking styles. Thus the memorial has been written. The social, educational, historical and epistemological processes contributed to the training, the academic and professional career. The relation between specific and general is remarkable as it draws the picture of a professional educator committed to students and the quality of teaching. If there was any doubt whether participating in the selection process, at the end it became evident to the author that there is still a lot to do in the field of Education.
\end{abstract}

Keywords: Sociocultural processes. Education. Memorial. 
"Ser autor é assumir suas ideias no melhor e no pior. (...) Preciso dizer que esta exibição comporta também a humildade" MORIN (2006).

Recordar é viver. Ao escrever esse memorial pude sentir as alegrias, as frustrações e as dores dos eventos lembrados. Inicialmente, fiquei contrariada por ser um requisito de inscrição, segundo o edital $n^{\circ}$ 79/2010 da Propeg/UNIPLAC, para o processo de seleção: docente/Mestrado.

Mas ao iniciar a narrativa fui envolvida e, às vezes de forma cronológica, outras de forma mais multifacetada, fui construindo cada capítulo. O capítulo: "Chegando à universidade", foi delicioso! Pude sentir o "medo do mar"... como senti quando, na Graduação em Ciências Biológicas, durante as pesquisa a campo, tínhamos que utilizar barcos.

O memorial consta de três capítulos. No capítulo I - "Os primeiros tempos." - faço uma viagem a minha infância e adolescência durante as quais foram construídas as bases valorativas que me permitiram ser uma pessoa íntegra e ética, com capacidade de discernimento e de fazer escolhas. Saliento a importância da família e da escola nessa construção.

No capítulo II - "Chegando à Universidade" - falo a respeito da minha formação acadêmica. A hora... é agora ou agora é hora... Esse trocadilho é uma referência ao tempo propício para os acontecimentos da nossa vida, no caso para os cursos de graduação e pós-graduação. No meu caso, eles ocorreram dentro de um contexto profissional e de inquietudes intelectuais que eu vivenciava.

No capítulo III - "Trajetória Profissional: uma rede de experiências" - trato da docência na Educação Básica e dos Caminhos no Ensino Superior. 
Nesses mais de 20 anos de UNIPLAC, sempre atuei fortemente no Ensino, na Pesquisa e na Extensão Universitária. Meu desejo é, no futuro profissional, dedicar mais tempo e energia à área de Pesquisa.

\section{I - OS PRIMEIROS TEMPOS}

Como uma criança, um jovem, uma pessoa - nas diferentes fases de sua vida percebe seu entorno? Como estabelece as relações com os outros e com o ambiente? Aqui eu começo minha narrativa, tentando explicar como construí meu futuro com base nas nas minhas percepções, vivências e escolhas.

Sou a sexta filha do Seu Ernesto e da Dona Maurillia. Que casal! A barulhenta família de origem italiana, com valores definidos, objetivos claros e a certeza de que teríamos que estudar. Quando adolescente, no Ensino Fundamental e, depois, no Ensino Médio, eu era destaque como atleta de esporte coletivo: handebol e modalidades de atletismo: lançamento de dardo, de disco e arremesso de peso. Estas habilidades possibilitaram bolsa de estudos na melhor escola confessional da cidade e assim pude me preparar para o vestibular.

O vestibular: hora da escolha. Para os familiares e amigos parecia evidente que eu faria Educação Física. Uma das minhas irmãs já era graduada nessa área. A outra irmã havia concluído psicologia. O meu irmão estava concluindo graduação em Química. Aí, a surpresa da opção por Ciências Biológicas.

Quando pequena eu andava pela chácara e tinha domínio sobre todos os cantinhos e, entre tantas curiosidades, havia uma que me fascinava e ainda fascina: “pedras”. Havia lugares - era segredo - onde havia pedras que pareciam diamantes, pelo modo como brilhavam, pela forma e pelas cores...

E a lavoura, com seus gostos...! Eu adorava passar pelos canteiros e tirar folhas das verduras; fazia um rolinho e comia. E o mais gostoso era conseguir identificar cada gosto na mistura da mastigação. As ameixas eram os frutos provenientes das mudas que 
os nonos haviam trazido da Itália. Nunca mais senti "aquele" sabor, pois uma doença matou as duas árvores.

Quando o Prof. Mário Sérgio Cortella fala que está faltando "pamonharização" para as crianças de hoje, ou seja, o envolvimento delas em todas as etapas do processo de fabricação das pamonhas - o que equivale a dizer que está faltando, às crianças de hoje, o seu envolvimento completo nos diferentes processos da vida cotidiana - eu me reporto aos dias em que ocorria a transformação dos suínos em proteína para a família. Era uma "festa", os adultos começavam a preparar tudo que era necessário dois dias antes - era um ritual. Todos tinham suas tarefas, atribuídas e realizadas de acordo com a idade. Eu lembro até hoje do aroma dos temperos e da vinha d'alho para a carne com a qual se faria o salame. Como eu era a menor, eu sempre fazia as tarefas que me permitissem ficar próxima ao pai e à mãe, por exemplo, organizar os temperos e ajudar com os utensílios.

Ah! Havia também os terneirinhos que tinham que receber mamadeira quando a mãe os rejeitava, ou a vaca que, literalmente, chorava e não parava de berrar se seu bezerro fosse separado dela.

Tem mais, eu sou do tempo em que havia programas educativos como "Mundo Animal” e "As Aventuras de Jacques Cousteau". Como tínhamos horários para assistir TV e os programas eram selecionados, eu trocava tudo para assistir aos dois programas citados. Minha mãe dizia: “- Você vai ser cientista! Como gosta desses personagens e desses programas!” Até hoje minha família me "critica” pela forma como eu ficava diante da TV - e, às vezes, ainda fico se o assunto me interessa - totalmente concentrada, pois “viajo"... Ficava encantada com as manadas de elefantes, com a capacidade deles em reconhecer os locais onde morreram seus parentes e pelo cuidado com os filhotes.

Minhas disciplinas preferidas sempre foram Ciências, Geografia e Biologia. No Ensino Médio tive um professor maravilhoso, Prof. Ernesto Daniel, que nos levava para o jardim da escola para observar as plantas e os animais.

Embora muitas pessoas tenham falado: "-Se gosta de animais, faça o curso de Medicina Veterinária, inclusive tem aqui em Lages, não precisa ir a Florianópolis”, nunca 
pensei em cursar veterinária; esse seria o Curso certo para meu irmão, porém ele partiu muito cedo, quando estava perto de fazer vestibular.

Mas o pior mesmo foi quando escolhi Licenciatura e não o Bacharelado. Fazia-se a opção na inscrição do vestibular. Algumas pessoas achavam um absurdo sair de casa com o fim de estudar para ser professora... Se, ao menos, fosse Bioquímica...

Entretanto, meus pais respeitaram a minha escolha e me apoiaram, assim como haviam feito com meus irmãos. Inclusive venderam o sítio para minha mãe não ficar sozinha e ficaram só com a chácara.

O importante dessa situação é que não foi sequer cogitada a hipótese de eu não ir para a Universidade, considerando-se, inclusive, as dificuldades financeiras que teriam para manter-nos - a mim e a meu irmão - em Florianópolis. Como meus pais são generosos e sábios!

Esse contexto apresentado sem preocupação temporal linear formou uma rede de interações complexas das percepções e das relações que construí, acerca e do meu entorno. O peso da formação familiar e da Educação escolar é que me levaram à escolha do curso de Ciências Biológicas e à construção do meu futuro profissional.

\section{II - CHEGANDO À UNIVERSIDADE}

\subsection{Graduação em Ciências Biológicas - A hora de aprender}

Que experiência significativa, na minha vida, foi a graduação! Primeiramente, fui morar fora, embora com irmãos por perto. Sempre aprendemos muito longe de casa.

As aulas, os professores, os laboratórios, os colegas, o conhecimento, a iniciação a pesquisa, tudo foi e continua sendo referência na minha vida. É o peso da formação:

(...) os conhecimentos compõem-se em sua maior parte do aprendido, não do novo. Porém, há de se ter presente que toda transmissão de conhecimento, durante o processo de aprendizagem, acontece deforma imperceptível (...) (FLECK apud SCHAFER e SCHNELLE, 1986, p.20). 
Cheguei a Florianópolis, na UFSC, em 1980, na efervescência das greves e da abertura política. Convivemos com alguns seres estranhos, de jaqueta de couro, que ficavam olhando de longe e até tentaram pedir para "a gente" contar o que os professores diziam em sala. Eu cheguei a Florianópolis logo após a NOVEMBRADA (30/11/79).

Em 1983, tive uma professora de Fundamentos da Educação, Profa. Telma Piacentini, a qual me apresentou o primeiro texto de Marx. Inclusive, eu escolhi fazer, com ela, uma disciplina optativa - Fundamentos da Educação II - enquanto meus colegas fizeram Imunologia, Microbiologia, Genética... Hoje essa professora atua no Mestrado em Educação, da UFSC. E os trabalhos a campo: coletas na praia, no mangue, visitas às ilhas e... o "medo do mar"!... Eu sou da montanha...

Continuava gostando da área específica e me identificando cada vez mais com a área de Educação. Chegou o momento do Estágio, no Colégio de Aplicação. Foi muito gratificante. Inclusive, a professora de Biologia da Aplicação, Profa. Delmar me indicou para substituí-la, durante a sua Licença Prêmio, na Escola Estadual Getúlio Vargas. Foi meu primeiro emprego.

Todavia meu maior aprendizado no Estágio foi com minha supervisora, Profa. Marialva Golin. Os conteúdos que eu trabalhei foram o metabolismo da respiração celular e a fotossíntese. Conteúdos de que alguns professores correm, pela densidade do assunto.

Lá pela metade do Estágio, na aula em que eu explicaria a respiração celular mitocondrial, fiquei tensa e esqueci - “deu um branco". A professora da sala e a supervisora começaram a conversar com os alunos e a aula acabou.

No final da aula a Profa. Marialva disse: “-Lúcia, não se preocupe. O Estágio não é prova de memória. Amanhã você continua sua aula. Eu sei que você estudou e sabe o conteúdo." E assim aconteceu.

Essa foi uma grande lição, eu era mais do que aquele conteúdo, eu não fui avaliada pelo que deixei de fazer, mas por tudo o que já havia apresentado no Estágio e no Curso. Isso foi muito significativo para minha vida profissional. 
Concluí o Curso, colei grau dois meses depois da data prevista, pois, em todos os oito semestres do Curso vivenciei greves na Universidade.

\subsection{Cursos de Especialização - A hora de definir-se}

Em 1985, casei e comecei a trabalhar como professora de Biologia e Ciências. Em 1986 comecei um curso de Especialização em Biotecnologia, na UCS, já que planejei um mestrado na área de Botânica ou de Genética. O curso de Biotecnologia tinha como foco a produção de bebidas fermentadas - vinho. Assim, realizei vários experimentos controlados e complexos. Em 1988 nasceu meu primeiro filho, e eu me afastei do projeto de Mestrado.

Na prática docente eu começava a me questionar sobre a forma de avaliação e sobre o significado dos conteúdos para os alunos.

Comecei a desconfiar das verdades científicas. O modelo de reprodução aprendido na Universidade já não correspondia mais ao que se sabia e ensinava, já que a fecundação poderia ocorrer numa proveta; e a formação de um novo ser (clone) se tornava possível sem a presença de gametas.

Em 1991 nasceu meu segundo filho e comecei uma Especialização em Educação, na UNIPLAC. Esse foi sem dúvida um marco referencial na minha formação acadêmica e, consequentemente, na minha vida profissional.

O Curso me proporcionou conhecer o Prof. Selvino Assmam e ele me levou a entender a unicidade do conhecimento, a construção histórica e dogmática da hierarquia entre as áreas de conhecimento, que a ciência e os cientistas não são neutros, que as verdades são transitórias, assim como as relações de poder na sociedade. Enfim, foi uma experiência de aprendizagem e uma mudança de paradigmas, ambas intensas.

O curso de Especialização em Educação foi fundamental como preparação para o Mestrado em Educação - Linha: Educação e Ciência - UFSC, pois nessa época não cogitava mais realizar um Mestrado na área específica de Biologia. 
Em 1995, a UNIPLAC ofereceu aos seus professores um Curso de Especialização em Metodologia da Pesquisa, que em 1996 consegui concluir, mesmo estando no Mestrado. Foi importantíssimo para os caminhos da orientação e da Pesquisa.

\subsection{Mestrado em Educação - A hora de aprender a pesquisar}

A seleção para o Mestrado em Educação, da UFSC, foi em 1995. Foi um processo, no mínimo, curioso, que iniciou com quatro professores de Lages: eu e mais três colegas, que fomos a Florianópolis para fazer a inscrição e entregar o Projeto. Na etapa seguinte, que foi a prova de conhecimentos, só foram selecionadas eu e uma das colegas, e, finalmente, para a entrevista, eu fui sozinha. Dois anos depois outros colegas foram fazer o Mestrado em Educação, em outras linhas de pesquisa e, em 1997, o Mestrado foi oferecido interinstitucionalmente, ocasião em que vários outros colegas da UNIPLAC cursaram-no em diferentes linhas de pesquisa.

Nesse período, por certo vivenciei o mais intenso aprendizado, haja vista que participava de um seleto grupo de trabalho, constituído por professores da Secretaria de Educação de Santa Catarina, com o objetivo de elaborar a Proposta Curricular de Santa Catarina (Ciências, Biologia, Física, Química e Educação Ambiental) grupo este que contava com encontros com consultores nas Áreas de Educação e nas Áreas Específicas do conhecimento.

Como em 1989 ingressei na docência, no Ensino Superior, e fui assumindo disciplinas pedagógicas, além das de formação específica, passei a trabalhar tanto na formação inicial como na formação continuada de Professores. Esse foi o foco da dissertação do Mestrado: “Formação de Professores de Ciências: Uma Abordagem Epistemológica". A pesquisa, durante o Mestrado me levou à reflexão sobre o peso que tem para o ensino, a formação dos professores de ciências e sobre a possibilidade de construir outro estilo de pensamento.

(...) cada coletivo de pensamento elaborou um estilo de pensamento "único", composto pelo conjunto de normas, saberes e práticas partilhadas por dado Coletivo. (FLECK apud SCHAFER e SCHNELLE, 1986, p.23). 
Identificamos as zonas de não resistência dos egressos dos cursos de ciências e matemática, para assim atuarmos com esses professores. Formação Continuada - Grupo de Ciências, com aproximadamente 90 professores da Rede Municipal e Estadual. Portanto, o que exatamente buscávamos? O que o peso da formação não permite: a mudança de estilo de pensamento.

Trata-se da possibilidade de mudar as normas, saberes e práticas partilhadas por um dado estilo de pensamento de um coletivo de pensamento. Está relacionado ao progresso do conhecimento e consiste no desenvolvimento coletivo de Estilo de Pensamento e tem três etapas: Instauração, Extensão e Transformação do Estilo de Pensamento. (FLECK apud SCHAFER e SCHNELLE, 1986, p.20).

Assim, identificar aqueles professores que "instauram" a possibilidade de mudança de Estilo de Pensamento, no sentido de construir outra prática docente que não a repetição irreflexiva do seu fazer pedagógico, é necessário para estabelecer outros fazeres pedagógicos.

Em meio a toda essa complexa rede de ações, constituídas pela docência no Ensino Superior (não houve liberação para participação no grupo multidisciplinar, para cursar o mestrado) e pela realização do curso de Mestrado, atuava, ainda, em fóruns, cursos e discussões sobre a questão ambiental que, em 1992, com a Rio 92, foi colocada em evidência. Havia demanda para atuar em Educação Ambiental na Formação de Professores, nos cursos de extensão Universitária, e em projetos de pesquisa.

A questão ambiental aparece como sintoma da crise da razão da civilização moderna, como uma crítica da racionalidade social e do estilo de desenvolvimento dominantes, e como uma proposta para fundamentar um desenvolvimento alternativo. (...) Aponta para a geração de novos conhecimentos teóricos e práticas para construir uma racionalidade produtiva alternativa. (LEFF, 2002, p. ix).

\subsection{Doutorado em Engenharia Ambiental - A hora de novos desafios na pesquisa}

Em 2000 comecei a refletir sobre o curso de Doutorado. Essa escolha foi a mais difícil que tive de fazer em termos de formação acadêmica. 
O problema: como continuar atuando na área de biologia - com ênfase na área de Ecologia - e na área de Educação - com ênfase na Formação de Professores?

Em 1996 participei de um Projeto: "Viva Floresta Viva - Educação Ambiental” com o Prof. Daniel José da Silva, da Engenharia Sanitária e Ambiental da UFSC. Esse projeto buscava capacitar professores da Rede Pública Estadual e técnicos da EPAGRI, de cada região de Santa Catarina, e que já atuavam em Educação Ambiental. Esse projeto foi muito importante, pois além do grupo de professores de ciências, criamos, na Região, um grupo de professores para discutir Educação Ambiental.

Esses trabalhos, na sequência, foram interrompidos, pois, historicamente, com as mudanças dos dirigentes públicos a maioria dos projetos não tem continuidade. Mesmo assim, continuamos com trabalhos nas unidades escolares e principalmente na orientação de TCCs, dos cursos de graduação.

Assim, comecei a procurar um curso de doutorado que atendesse as duas áreas do conhecimento: Biologia e Educação.

Os cursos existentes eram em programas puros, portanto, a interface ficava difícil por não ter quem orientasse, ou não cabia nas linhas de pesquisa dos programas.

Em 2001, resolvi conversar com o Prof. Daniel José da Silva, da Engenharia Sanitária e Ambiental/UFSC. O programa de Pós-Graduação é em Engenharia Ambiental e as linhas de pesquisa permitiam a interface entre Biologia (Ecologia)/ Educação, ou seja, eu poderia fazer uma tese em Educação Ambiental. A minha titulação na graduação em Ciências Biológicas foi no CCB (Biologia), o mestrado no CCE (Educação) e o Doutorado seria no CCT (Tecnológico). Isso pode parecer esdrúxulo, principalmente para quem não tiver a oportunidade de ler este "Memorial" e não conhecer a minha trajetória profissional, que, desde a graduação, tem sido em uma única linha: Formação de Pessoas (alunos e professores) e a sua relação com o ambiente. Para tanto, precisamos conhecer a complexidade ambiental nas suas dimensões abióticas e bióticas, temos que compreender como o conhecimento é produzido, como se dá o processo ensino/aprendizagem e os processos de identificação de problemas ambientais e de suas soluções. 
O doutorado me apresentou a teoria dos sistemas, da complexidade, e a transdisciplinaridade. Então, entendi que o meu fazer era transdisciplinar e eu transitava por muitas dimensões da realidade, e que isso me permitia fazer parte de uma rede de interações complexas. Entendi também porque o Prof. Daniel me aceitou como orientanda, já que eu seria uma bióloga educadora no meio da "engenheirada". Não foi muito fácil, mas eu já sabia.

Assim, em 2007, defendi minha tese: “Processo de Planejamento e Implantação do Parque Natural Municipal de Lages - SC", com ênfase na conservação das Bacias Hidrográficas e na Percepção da Comunidade do Entorno.

Essa tese foi construída em meio a minhas atividades docentes do Ensino Superior (Ensino, Pesquisa e Extensão) e da Educação Básica, já que não obtive licença para cursar o Doutorado. No percurso teórico entendi que fora essa complexa teia de situações que permitira a elaboração da tese, a qual, assim entendo, reflete essas diversas dimensões de realidade. Durante toda a minha formação acadêmica, desde os cursos de especialização até o doutorado, convivi com duas situações: a da minha discência e a da minha docência. Certamente exigi de mim mesma muito cuidado e maturidade acadêmica para manter o distanciamento necessário do objeto de pesquisa, para realizar as reflexões e elaborações teóricas.

A trajetória de formação acadêmica apresentada proporciona-me certa tranquilidade para atuar na construção de novos estilos de pensamento voltados a um desenvolvimento que seja sustentável.

\section{III - TRAJETÓRIA PROFISSIONAL: UMA REDE DE EXPERIÊNCIAS}

\subsection{Aprendendo na Docência da Educação Básica}

Em 1984, ainda estudante de Biologia, já iniciei no Magistério Público Estadual como professora de Ciências e de Biologia, em Florianópolis. Como já mencionei no capítulo anterior, foi meu primeiro emprego.

Foi uma boa experiência já que era uma escola grande e me encaminharam para três turmas de "repetentes" da $8^{\text {a }}$ série, com toda sorte de "problemas" (aprendizagem, 
indisciplina, drogas, etc.) e consegui, talvez até pela minha pouca idade que se aproximava da deles, uma boa relação com os alunos, criando um ambiente favorável para o trabalho.

Concluí o Curso e retornei para Lages, onde fiz inscrição para atuar como “professor em caráter temporário" (ACT), no Magistério Público Estadual. Fui selecionada para trabalhar, em 1985, com carga horária de 40 h.a., no município de Correia Pinto. Ministrava aulas de Ciências para o Ensino Fundamental e de Biologia para o Ensino Médio e para o Técnico Profissionalizante. O Diretor dessa escola era o Padre Dilmar Sell, um progressista que acompanhou o movimento de Teologia da Libertação, lembrando que, em 1985, Leonardo Boff sofreu processo junto à Igreja, perdendo suas funções. O Padre Dilmar também era Pároco da cidade, a qual havia sido emancipada em 10 de maio de 1982.

Como ele entendia que a Educação era fundamental para a libertação das pessoas, preocupava-se com a qualidade do ensino e sabia que o material didático era muito importante, já que os alunos não tinham acesso a livros.

Conseguiu apostilas para todos os alunos da escola. Eu fui ter com ele. Manifestei minha opinião, dizendo-lhe que o material era importante, mas poderia engessar o fazer pedagógico. Ele disse: “- Professora, o material é um auxiliar. Você continua sendo a professora." Saí da sala e fiquei pensando como fazer algo para que os alunos se apaixonassem pelo conteúdo disciplinar utilizando o referido material. Então, depois de alguns dias, propus, em todas as séries/turmas, desenvolvermos projetos na área de Ciências e Biologia.

Os grupos de alunos escolhiam - de acordo com sua curiosidade e vontade de aprender - temas propostos conforme o conteúdo de cada série.

No final do ano, por dois dias, a escola só teve aulas em forma de apresentação dos referidos trabalhos, nos quais toda a comunidade havia sido envolvida. Foi um ano de muito trabalho, muita aprendizagem e de satisfação por perceber que era possível atuar de outra forma. 
Em 1996, eu continuava na condição de ACT, mas consegui aulas em Lages. Fui trabalhar também em escola particular, na mesma em que eu havia sido bolsista como atleta.

Era uma sala com um terceirão/ pré-vestibular, com 180 alunos. Eu precisava de microfone e havia um diretor de disciplina que permanecia em sala. Fiquei duas semanas e agradeci. Tinha certeza que não era nesse tipo de sala de aula que eu poderia realizar o trabalho para o qual havia me preparado. Então fiz o Processo Seletivo para a Fundação Educacional de Santa Catarina - FESC - uma autarquia estadual que abrigava as escolas técnicas profissionalizantes e a UDESC. Aprovada, iniciei com 20 horas semanais que depois foram ampliadas. Era uma escola modelo. E continuava trabalhando o restante da carga horária em outras escolas, como ACT. Em 1988 realizei o Concurso Público da Secretaria da Educação, de Santa Catarina, e, aprovada, fui atuar numa escola estadual próxima à "antiga” zona de meretrício.

Para resumir, os professores, à noite, saíam em comboio com os carros. O que mais chamou a atenção é que independente da história de cada aluno, entendi que aluno era aluno em qualquer escola. Eu era o instrumento que poderia contribuir para mudar algumas histórias.

Em 1987 eu ministrei aulas na outra escola confessional, que no início do século XX era só para moças. Eram várias turmas de Ensino Médio onde estavam as meninas da elite serrana. Como, nesse mesmo período, eu trabalhava também em escolas públicas e, igualmente, no Ensino Médio, algo me incomodava.

Na escola particular as meninas tinham seus longos e quase sempre louros cabelos, que eram jogados de um lado para o outro; eram extrovertidas, comunicavam-se bem, e a miss brotinho, a "miss Lages", geralmente, saíam daquele grupo. Nas escolas públicas as meninas também eram bonitas, mas diferentes. Qual era a diferença? Demorei um “pouquinho" para entender. Eram as condições materiais concretas de cada grupo. Os produtos de higiene e beleza, acesso a revistas, jornais, bens culturais, viagens... Quando me refiro à beleza e à diferença, uso essas palavras como uma metáfora, para chamar a atenção, para dizer que na essência eram iguais, tinham a mesma capacidade 
cognitiva, e que o meu trabalho e dos meus colegas é que contribuiriam para minimizar essas diferenças. Naquele ano, os alunos da Escola Pública, $3^{a}$. Série, obtiveram um índice de aprovação de $80 \%$ em vestibulares.

Em 1989, a FESC foi extinta e passei para o regime jurídico único de trabalho, permanecendo no CEDUP até o momento. É evidente que muito mudou lá na escola, ela não é mais "Escola Modelo", tem que se igualar às outras escolas estaduais. Cheguei a "sonhar" que as outras estaduais iriam tornar-se modelo também.

Hoje, salas projetadas para 25 alunos comportam turmas de mais de 40. 0 laboratório de biologia virou sala de aula e os equipamentos foram literalmente jogados numa sala até à deterioração, enfim, essa escola todos nós já conhecemos.

\subsection{Os caminhos do Ensino Superior}

Em 1987 atuei como professora substituta no curso de Ciências de $1^{\circ}$ Grau, na UNIPLAC. Em 1988 retornei e, em seguida, prestei concurso e lá estou até o momento. Eu digo, sem medo de exagerar, que, profissionalmente, me constituí e me reinventei, por diversas vezes, na UNIPLAC. E isso me permite a certeza da importância dessa instituição na minha vida.

Atuei no Ensino, na Pesquisa, na Extensão Universitária e na Administração desta Universidade.

Até que o novo regimento seja implantado, dos cargos/funções eletivos só não estive como Reitora. Nunca perdi a dimensão da transitoriedade dos cargos/funções e nem deixei de pensar que, para assumir qualquer um deles, o requisito é ser Docente, pois é a docência que nos identifica, nos constrói, nos diferencia.

Dos órgãos superiores e Comissões, o que mais marcou foi o processo Estatuinte da UNIPLAC. Eram "homens da caverna", o tempo todo tentando dizer que já tinham saído de lá. Outro processo inesquecível foi a transformação das Faculdades FACIP e FACEC em Universidade do Planalto Catarinense. 
Quando, entre 1993-1995 fui cedida do Estado para a UNIPLAC, para atuar na Descentralização do Ensino, uma das colegas, a Prof. Cleusa Couto, olhou pela janela e disse: "Esse é o começo de um novo tempo para a UNIPLAC. Um dia teremos alunos, professores e cursos durante o dia também." E iniciamos nosso solitário trabalho. No período diurno só os serviços gerais e alguns funcionários do administrativo trabalhavam na UNIPLAC.

Um dos primeiros projetos foi o de Formação Continuada dos professores da Rede Pública estadual, em 1994, que reuniu 1.500 professores cursistas, 5 (cinco) polos, 32 professores da UFSC e a formação de Grupos de Trabalho por área do conhecimento, como citei no capítulo II, o Grupo de Ciências e o de Educação Ambiental.

E entre tantos outros Projetos e Ações executados por esses quatro professores do Estado, cedidos para a UNIPLAC, um merece destaque. O Curso Supletivo de Ensino Fundamental e Médio para titulação de Professores de Escolas Multisseriadas da Região Serrana, iniciado em 1994.

Esse projeto atendeu aproximadamente 300 professores leigos, que não tinham a Educação Básica e eram professores em suas localidades. Metodologicamente, tinham carga horária presencial. Nos períodos de aula presencial eram alojados no Instituto Vianei. Por se tratar de formação para magistério também, nós, professores do curso, acompanhamos os estágios nas suas salas de aula, nas diversas localidades e municípios. Todos aprenderam. Inclusive há monografias e dissertações que avaliaram a importância desse projeto.

Quanto à docência na graduação, de 1996 a 1998, realizei uma análise da Formação de Professores que resultou na minha dissertação, da qual já abordei alguns aspectos, no capítulo II.

Concomitantemente a tudo isso, com a nova LDB, a Licenciatura curta em Ciências deveria dar lugar a uma Licenciatura Plena. Então, em 1996, elaboramos o projeto do Curso de Ciências Biológicas que iniciou sua primeira turma em fevereiro de 1997 e está em funcionamento até hoje. 
Em 1993 fui chefe do departamento de Ciências e Matemática; depois, coordenadora do Curso de Ciências Biológicas e, assim, fui assumindo funções administrativas, representações em Conselhos, atuando ativamente na política de transformação das faculdades em Universidade e nos processos de Administração Universitária.

De 2006 a 2008 contribuímos com a Universidade atuando na Assessoria Técnica e Pedagógica - ASTEP - que teve como objetivo ser espaço de mediação da PROENS - PróReitoria de Ensino - nos processos de Gestão Pedagógica, Administrativa e Técnicocientífica, visando desenvolver ações fundamentadas nas diretrizes institucionais.

Esta assessoria atuou nos seguintes programas: expansão da graduação; PPP de cada curso; Estágios curriculares obrigatórios e não obrigatórios; capacitação docente da UNIPLAC; Processos de reconhecimento de curso; reestruturação curricular de cursos e capacitação para professores da Educação Básica.

Foi uma experiência interdisciplinar, densa e muito tensa. A instituição já estava em crise financeira antes de 2006. Então, as ações eram norteadas pelo custo zero. Dessa forma, não há disponibilidade de técnicas administrativas, não há como contratar uma consultoria, não foi possível implantar as políticas institucionais de Estágio à luz da atual legislação, não foi implantado o Programa UNIPLAC Virtual e não era possível convidar Professores renomados para capacitação docente. As comparações com tempos anteriores foram inevitáveis, mas as condições eram outras. Porém, mesmo nessas condições, como produto desse período foram, entre outras ações, elaborados 16 projetos de novos cursos. Esse número dimensiona o trabalho desse período na ASTEP.

Contudo, o cotidiano apresentado acima em nada influiu na forma como fomos desligados da função, no final de 2008. Soubemos pelo jornal local que estávamos exonerados. Algum tempo depois fui chamada, já sob a nova estrutura administrativa da UNIPLAC, por uma secretaria/assessoria para assinar minha exoneração: "Professora Lúcia, assine aqui." 
Como mencionei no começo do capítulo, sei da transitoriedade das funções e que meu cargo é Docente e primo por isso. Tanto que mesmo ocupando outros cargos nunca me desvinculei totalmente da sala de aula e das orientações de TCCs e monografias.

Assim, desde 2008 até esta data estou ministrando as disciplinas de Formação Profissional e os estágios do Curso de Biologia, além das disciplinas específicas como Biologia Celular e Sistemática de algas, liquens, fungos e briófitas.

Trabalho também no curso de Pedagogia, com Fundamentos de Ciências; no curso de Biomedicina, com Biologia Celular; e no curso de Administração, com a disciplina Administração Ambiental. A sala de aula é, para mim, um espaço prazeroso que escolhi para continuar aprendendo.

Na Pesquisa, desde 2008, coordeno a "Meta 5", "Componente 1" do Projeto “Rede Guarani - Serra Geral”, no qual temos já Resultados de Pesquisa, obtidos com alunos da Educação Básica, sobre percepção ambiental, resultados esses que servirão de base para a elaboração de artigos científicos.

Assim, nesses anos de ensino Superior, o emaranhado da teia dos fazeres acadêmicos apresentados nessa narrativa - o ensino, a pesquisa e a extensão - sempre foram realizados, de forma concomitante, sem valorizar de forma especial nenhuma dessas áreas, até porque não são antagônicas e sim complementares.

\section{Referências}

CORTELLA, M. S. Não Nascemos Prontos. Florianópolis: Escola do Legislativo da Assembleia Legislativa de Santa Catarina, 2007. (Palestra).

MORIN, Edgar. Introdução ao Pensamento Complexo. Porto Alegre: Sulina, 2006.

LEFF, Henrique. Epistemologia Ambiental. 3ª Ed. São Paulo: Cortez, 2002. 
LIMA, Lucia Ceccato de. Processo de Planejamento e Implantação do Parque Natural Municipal de Lages - SC com Ênfase na Conservação de Bacias Hidrográficas e na Percepção da Comunidade do Entorno. Florianópolis: UFCS, 2007 (Tese).

LIMA, Lucia Ceccato de. A formação de Professores de Ciências: Uma Abordagem Epistemológica. Florianópolis: UFSC, 1999.

SCHÄFER, L. e SCHNELLE, T. Los Fundamientos de la vision sociologica de LUDWIK FLECK e la teoria de la ciencia In: Ludwik Fleck, La génesis y el desarrollo de un hecho científico. Madri: Aliança Editorial, 1986. 